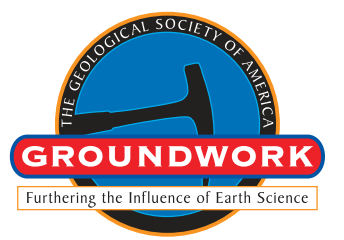

\title{
Geoscience Videos and Animations: How to Make Them with Your Students, and How to Use Them in the Classroom
}

Robert J. Stern*, Geoscience Dept., University of Texas at Dallas, Richardson, Texas 75080, USA, rjstern@utdallas.edu; Jeffrey G. Ryan, School of Geosciences, University of South Florida, Tampa, Florida 33620, USA, ryan@mail.usf.edu; Ning Wang, Geoscience Dept., University of Texas at Dallas, Richardson, Texas 75080, USA, ning.wang@utdallas.edu; Victor Ricchezza, School of Geosciences, University of South Florida, Tampa, Florida 33620, USA, ricchezza@mail.usf.edu; and Siloa Willis, Geoscience Dept., University of Texas at Dallas, Richardson, Texas 75080,USA, siiloa.willis@utdallas.edu

We are in the midst of a "tectonic shift" in the way that undergraduate students want to learn. They will attend lectures and read assignments if they must, but they are especially interested in information that they can receive as videos on their cell phones and other mobile devices (Prensky, 2001; Thomas, 2011). The geosciences are uniquely wellsuited to presentation via well-crafted, scientifically robust videos and animations. Geologic processes often take place over thousands to hundreds of millions of years and occur deep under water or within the Earth, where direct observation is not possible. Geology is synonymous with travel: Spectacular outcrops and Earth phenomena occur around the world, requiring photos and video to be accessible to most of us. Documenting natural disasters and the realities and impacts of climate change are highly amenable to presentation via videos and animations. Finally, videos and animations about the Earth allow these experiences to be shared with more diverse audiences. Sharing highquality videos and animations about Earth systems may stimulate student interest in the earth sciences and help address longstanding concerns about enrollments in geoscience degree programs. However, in spite of these considerations, the number of high-quality geoscientific videos to use for these purposes continues to be inadequate. We hope through this article to spark discussion about how to encourage more geoscientists to create scientifically accurate and engaging videos and animations of Earth processes.

Historically, generating video content and animations for education has been the purview of publishers, television producers, and videography professionals. However, with the advent of inexpensive video production equipment (including tablets and smartphones) and software (i.e., Adobe Creative Suite applications, Camtasia, IMovie, etc.), the tools for making good-quality video and animations have become widely accessible, and platforms such as YouTube make it easy to disseminate videos. Most geoscientists are not trained in storyboarding, making animations, recording sound, or editing video. Companies like Pixar and TV channels like National Geographic and Discovery have staff with much stronger technical skills in these areas than any geoscientist will likely have, and have the budgets to do longer, high-production-value geoscientific videos. However, what we geoscientists have that videography professionals lack is more important than big budgets: We know how the Earth works. We "tell the stories" of Earth processes and visualize them already, so with a basic understanding of video production —or, by leveraging our talented undergraduates, many of whom have been doing rudimentary video production and editing for years-we can produce our own scientifically accurate and visually engaging animations of important Earth phenomena.

It is easier and far cheaper for a motivated team of geoscientists to learn to make an educationally useful geoscience video than it is to get a videographer or animator knowledgeable enough in the geosciences to produce something of comparable educational value. Students involved in making geoscience video animations engage deeply and creatively with the content, learning our science better by making videos about it. Students interested in creating video on subjects they are learning aligns with the findings of the Speak Up Surveys and other longitudinal studies of change in STEM education on the preferences of today's "digital native" students to co-create content as a means of learning (i.e., Project Tomorrow, 2008; Rainie and Anderson, 2008).

Even if one agrees with the concept that geoscientists should be making educational videos and animations, why we would do so is less clear, as the drivers for faculty (tenure, promotion, a job, a graduate degree, etc.) are not obviously served via videomaking in the way that writing grants and peer-reviewed papers are. Fortunately, making video animations of Earth processes is relatively cheap, and one can incorporate the modest costs of making educational videos into NSF-funded projects as "broader impacts" activities. It is easy to post videos and animations to YouTube and to disseminate them widely through Facebook and other social media, as well as via email communities (e.g., GSA Open Forum, AGU Member Community, AAAS Member Community), and it is also easy to post videos to a dedicated website (UTD Geoscience Studios, https://utdgss2016 .wixsite.com/utdgss, hosts all of our geoscience videos and animations, and we also maintain a YouTube channel). There are no obvious outlets for papers discussing the production or educational potential of geoscience animations or videos; however, Stern et al. (2017) recently published a paper on an $\approx 9$ min geoscience animated video, "Plate Tectonic Basics 1" (https://www .youtube.com/watch? $v=6 \mathrm{wJBOk} 9 \mathrm{xjto} \& \mathrm{t}=10 \mathrm{~s})$, that explains how oceanic lithosphere is created at spreading ridges and destroyed in subduction zones. About 18,000 people have watched it on YouTube as of March 2020. No geoscience-specific recognition for outstanding videos has yet been estab-

GSA Today, v. 30, https://doi.org/10.1130/GSATG451GW.1. Copyright 2020, The Geological Society of America. CC-BY-NC.

*Corresponding author. 
lished, though, periodically, NSF posts competitions for innovative researcher or student videos related to its funded research (see as an example https://www.youtube .com/watch?v=g4IiUTZ_XsU).

The educational impacts of student use of video animations of geoscience phenomena as compared to traditional instructional modalities have not been well studied. We obtained IUSE-EHR Program Exploratory grant funding to assay both how to make effective video animations of tectonic processes and to see if using these videos in geoscience courses leads to improved student understanding of these natural phenomena. Our project has leveraged the interests of University of Texas at Dallas (UTD) undergraduate and graduate students, affording them an opportunity to develop basic videography and animation skills in the context of a UTD course, "Geoscience Videos and Animations" taught by the first author. A nine-minute video about this course is at https://www .youtube. com $/$ watch? $\mathrm{v}=\mathrm{k} 2 \mathrm{LYe} 9 \mathrm{DqGx} 0 \& \mathrm{t}=9 \mathrm{~s}$. The course targets upper-division geoscience majors, who by this stage know a lot of geology, and gives them the means to explore a geologic topic of interest via making their own video animation about it. The class does not depend on the video-making or animation skills of the first author (which are extremely limited!), as the students are eager to learn and teach each other the use of videography and animations software. We use Adobe Creative Suite applications to make video animations, Illustrator (AI) for figures and animation elements, Premiere Pro for editing, and After Effects for animation and special effects. The ability to make a video or animation is a job skill, and students like being able to add this to their résumés.

Assessing the instructional benefits of a geoscience animation can take different directions depending on what one wants to know. In our project, we are most interested in whether students can accurately recall the workings of dynamic, deep-Earth processes, and whether the video format is a comfortable and effective way for them to learn that content. We are using the ConceptSketch assessment approach (Johnson and Reynolds, 2005) along with written responses to measure learning, and short interviews with students to assay their views on the videos and gather formative data for refining the videos. We've collected classroom data on two UTD videos (Three Great Ways to Melt the Mantle: https://www.youtube.com/watch?v= LqWVXRtcSiA\&t=90s; Continental Rifts, Ocean Basins and Passive Continental Margins: Plate Tectonics Basics 2: https:// www.youtube.com/watch?v=W6oJKsSiLEI\& $\mathrm{t}=26 \mathrm{~s})$. Student responses to the animations as instructional tools have thus far been uniformly positive, and their written and sketched responses point to improvements in learning, with some interesting complexities related to the recall of visual content.

Some pointers to keep in mind to start making your own geoscience videos or animations include:

1. Use animation sparingly. Video is much easier to do than animation: one minute of video can be made in $1 \%$ of the time it takes to generate one minute of a simple animation. Geoscience expertise plays a big role in making scientifically correct animations and largely decides how quickly one can make a geoscience educational animation.

2. Good sound is the most important part of any video. Recording good sound quality is a challenge, and good sound quality is critical to making videos and animations that students will want to use and that you will want to share.

3. Avoid lecturing. Try to tell a story about the topic of the video - a good storyboard is the first step in video making. Good stories make viewers want to learn more about the topic at hand.

4. People have short attention spans and will "click away" when they get bored. Most of the UTD geoscience videos are three to five minutes long; our 10-minute videos are more ambitious and target only upper-level students, who have longer attention spans for geoscience content.

5. Always include "closed captions." Closed captioning makes an animation or video accessible to the hearing-challenged, and it is also useful in noisy environments or when viewers don't want to disturb those around them. YouTube offers a closedcaptioning service for videos, but you will need to edit the captions before posting.

6. Guide viewers to where they can learn more. Use textbooks and peer-reviewed literature for the video content, and list these references at the end of the video.

7. Give credit generously, wherever it is due, for images downloaded from the Internet, for experts interviewed, and to those who helped put the geoscience animation or video together: the best videos are ultimately team efforts.

\section{REFERENCES CITED}

Johnson, J., and Reynolds, S., 2005, Concept sketches - using student and instructor generated annotated sketches for learning, teaching, and assessment in geology courses: Journal of Geoscience Education, v. 53, p. 85-95, https://doi.org/ 10.5408/1089-9995-53.1.85.

Prensky, M., 2001, Digital Natives, Digital Immigrants Part 1: On the Horizon, v. 9, no. 5, p. 1-6, https://doi.org/10.1108/10748120110424816.

Project Tomorrow, 2008, Speak Up 2007 for Students, Teachers, Parents \& School Leaders: Selected National Findings: http://www.tomorrow .org/speakup/ (last accessed 10 Mar. 2020).

Rainie, L., and Anderson, J., 2008, The Future of the Internet III: Pew Internet and American Life Project, https://www.pewresearch.org/internet/ 2008/12/14/the-future-of-the-internet-iii/ (last accessed 20 Mar. 2020).

Stern, R.J., Lieu, W., Manley, A., Ward, A., Fechter, T., Farrar, E., McComber, S., and Windler, J., 2017, A new animation of subduction zone processes developed for the undergraduate and community college audience: Geosphere, v. 13, p. 628-643, https://doi.org/10.1130/GES01360.1.

Thomas, M., 2011, Deconstructing Digital Natives: New York, Routledge, Young People, Technology, and the New Literacies, https://doi.org/ $10.4324 / 9780203818848$.

MANUSCRIPT RECEIVED 21 JAN. 2020

MANUSCRIPT ACCEPTED 26 FEB. 2020 